\title{
The Effect of Voting Advice Applications on Political Knowledge and Vote Choice
}

\section{Naomi Kamoen, Bregje Holleman, André Krouwel, Jasper Van de Pol \& Claes de Vreese}

To cite this article: Naomi Kamoen, Bregje Holleman, André Krouwel, Jasper Van de Pol \& Claes de Vreese (2015) The Effect of Voting Advice Applications on Political Knowledge and Vote Choice, Irish Political Studies, 30:4, 595-618, DOI: 10.1080/07907184.2015.1099096

To link to this article: https://doi.org/10.1080/07907184.2015.1099096

曲 Published online: 20 Oct 2015.

Submit your article to this journal \ulcorner

Џll Article views: 666

View Crossmark data \lceil

Citing articles: 10 View citing articles $\longleftarrow$ 


\title{
The Effect of Voting Advice Applications on Political Knowledge and Vote Choice
}

\author{
NAOMI KAMOEN*,**, BREGJE HOLLEMAN*, \\ ANDRÉ KROUWEL ${ }^{* * *}$, JASPER VAN DE POL ${ }^{* * * *} \&$ \\ CLAES DE VREESE****
}

*Utrecht Institute for Linguistics OTS, Utrecht University, Utrecht, The Netherlands; ${ }^{* *}$ Department of Communication and Information Sciences, Tilburg University, Tilburg, The Netherlands;

**** Department of Communication Sciences, VU University Amsterdam, Amsterdam, The Netherlands;

Amsterdam School of Communication Research, University of Amsterdam, Amsterdam, The Netherlands

\begin{abstract}
In many countries with multiparty systems, a decline in class voting has increased volatility and the need for comprehensive information about the political landscape among voters. Voting Advice Applications (VAAs) are online tools that match users to political parties and, as such, they hold a promise of reinforcing informational transparency and democratic representation. The current research investigated whether VAAs live up to this expectation by investigating to what extent VAAs affected users' political knowledge and vote choice in the Dutch national elections of 2012. Results show that VAA users feel that the VAA improved their political knowledge. In addition, those groups of VAA users who experienced a large knowledge increase, also relatively often indicated that their vote choice had been affected. This suggests that VAAs contribute to informational transparency by increasing knowledge among a potentially wide audience, and also that VAAs might increase democratic representation to the extent that VAAs persuade people to vote for the candidate that best represents their opinions. On the other hand, we found discrepancies between behavioural and perceptual measurements of the effect of VAAs on vote choice. This raises doubts about whether VAAs shape actual voting behaviours and knowledge, or rather perceptions of that.
\end{abstract}

Keywords: Voting Advice Applications (VAAs); voting behaviour; vote choice; political knowledge

Correspondence Address: NAOMI KAMOEN, Utrecht Institute for Linguistics OTS, Utrecht University, Trans 10 (Room 2.44), 3512 JK, Utrecht, The Netherlands. Email: n.kamoen@uu.nl 


\section{Introduction}

The erosion of traditional social class structures since the 1970s has led to many changes in western societies. One political consequence has been the reduced influence of class, religion and other structural cleavages on vote choice (e.g. Franklin et al., 1992; Garzia, 2010). Instead of ideological class voting, voters rely more and more on issue voting, which means that they base their voting decision on the perceived proximity between their own issue positions and those of political parties (Downs, 1957; Dalton, 2002). According to this voting strategy, voters develop their own opinions on issues, and inform themselves about the positions of political parties (Walgrave et al., 2008). However, in a complex political context with an increasing number of parties and candidates competing for one's vote (Garzia \& Marschall, 2012), it is hard to be up to date about all relevant issue positions of all candidates and parties running in the elections. In Ireland, for example, a total of 566 candidates contested the 2011 general elections, which was almost 100 more than in the previous general elections in 2007, and in the Netherlands during the 2012 national elections, where one votes for parties rather than candidates, voters could choose from 21 parties. Clearly, these numbers of (new) parties and candidates complicate the political landscape for voters. Furthermore, due to the increasing distance between citizens and politics, many voters simply do not feel motivated to spend their costly time on politics (Dumont \& Kies, 2012). That is why many citizens lack sufficient political knowledge, and why making a vote choice has become difficult for a substantial part of the electorate (Dalton, 2000).

A lack of political knowledge does not only affect individual voters, it also has its ramifications for democracy at large. This is because political knowledge is related to many attributes of good democratic citizenship, such as the acceptance of democratic norms, and participating in politics in a variety of ways including casting a vote and voting for a party or candidate that is consistent with one's own attitudes (Delli Carpini \& Keeter, 1996). In many countries such as Ireland there is a trend of decreasing turnout rates at elections (Murphy \& Reidy, 2012). In light of these consequences, one may argue that voters' lack of political knowledge impairs democratic principles (Delli Carpini \& Keeter, 1996; Wall et al., 2009).

Voting Advice Applications (VAAs) are online tools that attempt to inform users about the political parties and their standpoints (Garzia, 2010). While differing in some aspects (for an overview, see Garzia \& Marschall, 2012), VAAs share a common framework in which users indicate their opinions towards a set of issues relevant in a certain election (see Appendix 1). Based on the match between the parties' issue positions and the users' opinions, a VAA subsequently produces a personalised voting advice. Some VAAs provide an implicit advice by depicting the user in the political landscape, others display an explicit advice by showing a ranked list of those parties that match user preferences best (see Appendix 1).

The use of VAAs has become increasingly popular in Europe. The first VAA was introduced in the late 1980s in the Netherlands, by the semi-governmental organisation called Prodemos. While the first Dutch VAA, Stemwijzer (Vote Wiser), 
appeared on a floppy disk and sold only 50 times (De Graaf, 2010), the various online VAAs available today reach up to half of the electorate during national elections in the Netherlands (Garzia \& Marschall, 2012). In Germany and Switzerland, VAAs have been developed since the early 2000s and their usage has become widespread with 6.7 million Wahl-O-Mat users in the 2009 German elections (11 per cent of the electorate) and 1 million users of the Swiss VAA Smartvote in 2007 (20 per cent of the electorate) (see Garzia \& Marschall, 2012: 206). VAAs were first developed in Ireland for the 2009 local and European elections, reaching roughly 30,000 voters (Wall et al., 2009). If international trends are anything to go by, VAAs will continue to grow in usage in Ireland.

The informational function of VAAs combined with their huge popularity causes VAAs to have a high potential to increase political knowledge, thereby affecting political behaviours too (Andreadis \& Wall, 2014). Using the context of the 2012 Dutch national elections, we investigate whether VAAs live up to their potential and whether they affect users' political knowledge and vote choice. In doing so, we pay special attention to the question of which specific groups of VAA users are affected in their knowledge and vote choice the most. VAAs may be said to strengthen democratic representation if people who change their vote choice based on the VAA advice are precisely those who report increased levels of political knowledge. A change in vote choice would mean the 'new vote' better represents their interests and opinions.

\section{The Effect of VAA Usage on Political Knowledge}

The effects of VAAs on political knowledge have been investigated in several previous studies. In these studies VAA users are generally asked to indicate in a postVAA survey to what extent they feel that the VAA has increased their political knowledge, either directly or indirectly, by functioning as a stepping stone to look for more information. For example, in a study by Ladner (2012), 84 per cent of the VAA users indicated that the Swiss VAA Smartvote improved their knowledge about the elections. In addition, about 50 per cent of the VAA users stated that Smartvote motivated them to look for information about specific candidates or issues, and over 65 per cent reported that Smartvote encouraged them to discuss political issues with others. While comparable results were obtained in Germany (Marschall, 2005), an Italian study on cabina-elettorale.it reported the effects of VAAs to be more moderate. Only 21 per cent of VAA users in the Italian study felt encouraged to search for information and 41 per cent indicated that they were motivated to discuss the results of the test with others (De Rosa, 2010).

Clearly these studies show that VAA users experience a knowledge increase because of VAA usage. The reported size of the effect, however, varies between studies. This is probably due to various reasons (see also Andreadis \& Wall, 2014), such as the focus on different countries with different voting systems (Ladner, 2012), the low reliability of self-perception measures (Walgrave et al., 2008), the use of different question wordings (Garzia \& Marschall, 2012), and the 
timing of the question (post-VAA or post-election). In addition, concerns have been expressed about limited generalizability of the results of perceptual studies because of their reliance on non-random samples (e.g. Walgrave et al., 2008). To remedy some of these problems, this study measures the effect of VAAs on political knowledge at different points in time and in weighted and un-weighted data sets.

Some previous studies investigated to what extent the effect of VAAs on political knowledge varies between certain groups of VAA users. These studies have primarily focused on the difference in knowledge increase between younger and older VAA users - younger voters are expected to experience a larger knowledge increase because they are less informed about politics and therefore their potential to learn is relatively large (Hirzalla et al., 2010; Dumont \& Kies, 2012). Several studies affirm that the knowledge increase is particularly large for young VAA users (e.g. Ladner et al., 2009).

In this study we will go beyond the effects of age and other socio-demographic variables and test four key hypotheses related to cognitive characteristics of VAA users. The first characteristic of interest here is need for cognition (NfC). This trait has been defined as 'the tendency for an individual to engage in and enjoy thinking' (Cacioppo \& Petty, 1982: 116). Research has shown that NfC influences several behaviours, for example, individuals with a high-NfC report a more frequent consumption of news (Hallahan, 2009). In a political context, a high-NfC has been associated with more interaction about politics and more content-oriented usage of political media (Rudolph \& Popp, 2007). Therefore, we expect that VAA users are associated with relatively high levels of $\mathrm{NfC}$ in general. In addition, and more important for our purposes here, within the group of VAA users, it may be hypothesised that VAA users with a higher $\mathrm{NfC}$ will elaborate more on the VAA results than VAA users with a relatively lower NfC. Therefore, they may be expected to learn more from VAA usage as compared to users with lower levels of NfC. This is the first hypothesis we test in this study (H1.1).

Second, the knowledge increase due to VAA use may depend on an individual's political efficacy. This concept relates to the feeling of an individual to be able to influence the political process (Kaid et al., 2007). Previous research (e.g. Finkel, 1985) has found that efficacy consists of two components, internal efficacy which is defined as 'beliefs about one's own competence to understand, and to participate effectively in, politics' and external efficacy which is defined as 'beliefs about the responsiveness of governmental authorities and institutions to citizens' demands' (Niemi et al., 1991: 1407). We will measure both internal and external efficacy in this study but we expect the internal dimension to be the most important moderator for the effect of VAAs individuals who have a low internal efficacy and hence consider their political competence to be low are expected to learn more from VAAs than individuals who feel quite competent already (H1.2).

Third, we expect the certainty of one's vote choice to play a role. Research shows that citizens turn to a VAA with varying levels of certainty about their vote choice some have little clue for whom to vote whereas others have clear preferences (Ruusuvirta \& Rosema, 2009). In general vote uncertainty is found to be related to a lack 
of understanding of politics (Popkin \& Dimock, 1999). Therefore, we expect individuals who are quite uncertain about their vote choice to experience a larger increase in political knowledge due to VAA usage as their potential to learn from VAAs is probably larger than that of individuals who are certain about their vote choice already (H1.3).

Fourth, the primary reason for turning to a VAA is expected to be a relevant characteristic for predicting the knowledge increase due to VAA usage. VAA users probably have a variety of different reasons for turning to a VAA (e.g. Ruusuvirta \& Rosema, 2009; Dumont \& Kies, 2012). Some users may employ a VAA to learn something about politics while others may use a VAA just as a fun test. Based on the uses and gratifications approach (e.g. Farnsworth \& Owen, 2004), the intended reason for the usage of an internet tool determines what one gets out of it. We therefore expect that users who regard the VAA to be just a fun test will probably experience a smaller increase in political knowledge than other VAA users who consider the tool to be a serious advice instrument (H1.4).

\section{The Effect of VAA Use on Vote Choice}

As VAAs provide users with knowledge about the political landscape and advice for whom to vote, VAAs may also affect their users' vote choices (see also Ladner et al., 2012). Self-perception studies indeed show that VAAs influence vote choices. For example in a study by Ladner (2012), no less than 60 per cent of the VAA users reported that the candidate-based VAA Smartvote influenced their voting decision. In other countries with party-based VAAs the self-reported effect is more moderate. In the Netherlands, between 10 per cent (Kleinnijenhuis et al., 2007) and 15 per cent (Aarts \& Van der Kolk, 2007) of users indicate that they were affected whereas in Germany and Finland these percentages are about 6 per cent (Marschall, 2005) and 3 per cent (Mykkänen \& Moring, 2006), respectively. Taken together it shows that VAAs have a substantial impact on vote choice, but, as was also the case for political knowledge, the exact size of the effect varies substantially between studies. This picture is strengthened by several studies that have applied behavioural measurements, such as the percentage of VAA users voting for the party recommended by the VAA, to assess the effect of VAAs on vote choice (e.g. see Walgrave et al., 2008; Ruusuvirta \& Rosema, 2009; Andreadis \& Wall, 2014; Wall et al., 2014).

The effect of VAAs on vote choice has been shown to be moderated by at least three demographic characteristics of VAA users - the voting advice has a relatively large effect on women (Mykkänen \& Moring, 2006; Ladner, 2012), on individuals with a lower educational level (Mykkänen \& Moring, 2006) and on younger VAA users (e.g. Ladner, 2012). We expect to observe similar effects in this study but more importantly, we expect the effect of VAAs on vote choice to be affected by the same four cognitive characteristics of VAA users. The effects of these cognitive characteristics, however, are hypothesised to take a slightly different shape than for knowledge. 
First, we expect individuals with a low-NfC to display a larger effect on their vote choice than individuals with a high-NfC (H2.1). While VAA users with a high-NfC are expected to think about the results of a VAA more thoroughly, and therefore learn more from VAAs (H1.1), they are probably also more critical towards each piece of incoming information (Rudolph \& Popp, 2007). That is why we expect them to be less likely to adopt the advice than individuals with a low-NfC.

Based on similar reasoning we also expect individuals with a high rather than a low political efficacy (H2.2), and individuals who are certain rather than uncertain about their vote choice (H2.3) to be affected to a smaller extent. Just like individuals with a high-NfC, these groups of individuals are likely to hold strong political attitudes and therefore are less likely to alter their vote choice in response to new information (Zaller, 1992).

Finally, we expect a user's primary reason for turning to a VAA to have an effect. Based on the uses and gratifications approach (e.g. Farnsworth \& Owen, 2004), we presume that users who consider the VAA to be a serious advice instrument to vote for the party recommended by the VAA more often than VAA users who consider the VAA to be just a fun test.

All in all we expect VAAs to boost users' political knowledge and to affect vote choices. If the same users who experience relatively large knowledge increases also report the effect of VAAs on vote choice to be relatively large, there is indirect evidence to assume that VAAs affect vote choices because users are more informed about politics. If we find this to be the case VAAs are likely to have a positive effect on democratic representation.

\section{Method}

\section{Data Collection and Materials}

For this study, we draw upon a unique data set gathered through Kieskompas (Vote Compass), a VAA tool developed by the Free University of Amsterdam in 2006. After Stemwijzer (Vote Wiser), Kieskompas counts as the second largest VAA in the Netherlands. During the 2012 Dutch national elections, KiesKompas attracted approximately 1.2 million visitors. About 750,000 of them completed the vote test and received a voting advice. For each user who completed KiesKompas in the month prior to the 2012 elections (August 15-September 12), ${ }^{1}$ we created a log file in which we registered the answers to the VAA statements and the voting advice given by the application. In addition, we registered answers to questions about demographic variables, vote certainty, and the voting likelihood for each party (the propensity to vote or PTV; see Van der Eijk et al., 2006) that VAA users could optionally answer before receiving the voting advice (see Appendix 2; $N=$ about 515,000 for each question).

After users had received their implicit voting advice - their positioning in the political landscape - they were invited to participate in a survey about the use of the VAA. This post-VAA survey, among other items, contained questions measuring the 
perceived effect of VAAs on the respondents' political knowledge and vote choice (the dependent measures), as well as questions on their NfC, internal efficacy, external efficacy, and their main reason for VAA usage (the independent measures). Due to space limitations in the pop-up survey box, each concept was measured with only one question (see Appendix 3; $N=$ about 40,000 for each of these questions). ${ }^{2}$ The answers to all the questions in the post-VAA survey were added to the respondents' log files.

The last question of the post-VAA survey asked whether respondents were willing to contribute to additional research. The group of respondents who agreed $(N=$ $24,861)$ was sent an email with an additional survey on the day after the election. This survey again addressed the effect of the VAA on the users' political knowledge and vote choice (the perceptual dependent measures; $N=$ about 6,000 for each of the post-election questions). In addition, respondents in the post-election survey were also asked to indicate whom they actually voted for in the elections and from the answers to this question it was possible to construct a behavioural measure of the effect on vote choice (see the analysis section). The answers to the questions in the post-election survey were also added to the respondents' log files. The log files contain the actual voting advice given to the respondents and their answers to various survey questions measured at different points in time.

\section{Respondents}

Table 1 displays the demographic characteristics of the respondents in our various samples. As compared to the average Dutch voter, Kieskompas users are relatively younger, highly educated and more often male. Previous studies show that VAA users in different countries, such as Ireland (Wall et al., 2009) and Germany (Marschall, 2014), can be characterised in a similar way (male, young, and educated to higher-level). Therefore, we are confident that these tendencies do not indicate that our Kieskompas users are somehow 'strange' or 'biased' relative to other VAA users, but rather, that VAA users are in general not representative of the electorate at large in terms of demographic variables.

Table 1 also shows that when we compare the respondents in the post-VAA sample and respondents in the post-election sample to the population of Kieskompas users, ${ }^{3}$ several discrepancies occur. While these samples are relatively comparable with respect to educational level, men are over-represented and the young are under-represented in our samples. Therefore, and for reasons mentioned in the introductory part of this paper, we perform our analyses on both a pop-up survey sample and a postelection survey sample, and both on an un-weighted data set, and on a data set that was weighted to the population of KiesKompas users for stable demographic characteristics (age, gender, and educational level). ${ }^{4}$

\section{Analysis}

We take the post-election sample rather than the pop-up sample as a starting point, because the effects of VAAs on vote choice can be best measured after the actual 
Table 1. Descriptive statistics for different samples of respondents

\begin{tabular}{|c|c|c|c|c|}
\hline & $\begin{array}{l}\text { Eligible } \\
\text { voters }\end{array}$ & $\begin{array}{l}\text { All respondents } N \\
\text { (valid percentage) }\end{array}$ & $\begin{array}{c}\text { Post-VAA survey } \\
N \text { (valid } \\
\text { percentage })\end{array}$ & $\begin{array}{l}\text { Post-election } \\
\text { survey } N \text { (valid } \\
\text { percentage) }\end{array}$ \\
\hline \multicolumn{5}{|l|}{ Gender } \\
\hline Male & $49 \%$ & $306153(59 \%)$ & $26399(67.9 \%)$ & $4179(72.3 \%)$ \\
\hline Female & $51 \%$ & $212587(41 \%)$ & $12506(32.1 \%)$ & $1603(27.7 \%)$ \\
\hline \multicolumn{5}{|l|}{ Age } \\
\hline $18-34$ & $26.3 \%$ & $217118(42.2 \%)$ & $10067(25.8 \%)$ & $1041(17.9 \%)$ \\
\hline $35-54$ & $36.8 \%$ & $209160(40.7 \%)$ & $17476(44.7 \%)$ & $2161(37.1 \%)$ \\
\hline $55+$ & $36.9 \%$ & $87953(17.1 \%)$ & $11543(29.5 \%)$ & $2622(45 \%)$ \\
\hline \multicolumn{5}{|c|}{ Educational level } \\
\hline Low & $21.9 \%$ & $36146(7.1 \%)$ & $2738(7 \%)$ & $465(8 \%)$ \\
\hline Medium & $45.1 \%$ & $170714(33.5 \%)$ & $11524(29.6 \%)$ & $1677(28.9 \%)$ \\
\hline High & $33 \%$ & $302463(59.4 \%)$ & $24620(63.3 \%)$ & $3653(63 \%)$ \\
\hline \multicolumn{5}{|c|}{ Certainty about vote } \\
\hline $\begin{array}{l}\text { Sure whom } \\
\text { to vote for }\end{array}$ & & $90978(17.7 \%)$ & $13113(33.5 \%)$ & $2294(39.3 \%)$ \\
\hline $\begin{array}{l}\text { Hesitating } \\
\text { between } \\
\text { parties }\end{array}$ & & $249945(48.6 \%)$ & $19549(50 \%)$ & $2835(48.6 \%)$ \\
\hline $\begin{array}{l}\text { I don't know } \\
\text { yet }\end{array}$ & & $169625(33 \%)$ & $6299(16.1 \%)$ & $681(11.7 \%)$ \\
\hline $\begin{array}{l}\text { I am not } \\
\text { going to vote }\end{array}$ & & $3781(0.7 \%)$ & $163(0.4 \%)$ & $21(0.4 \%)$ \\
\hline
\end{tabular}

Note: The 515,000 (approximately) respondents who filled out their demographics, represent about 70 per cent of the population of KiesKompas users. As compared to the large sample of 515,000 respondents, respondents in the post-VAA survey and in the post-election survey are more often male, relatively older, relatively highly educated, and relatively more certain about whom to vote for in advance (in all cases a one-sample $\chi^{2}$-test gave $p<.001$ ). Comparable biases are found when we compare the post-VAA and post-election population with the population of Dutch voters at large. Our aim here, however, is to describe only the population of KiesKompas users; therefore the differences between our samples and the Dutch electorate at large are less important than the differences between our samples and the population of KiesKompas users.

elections rather than before. Below, we will elaborate on the regression models used for testing our hypotheses. Due to the large size of our samples we test our hypotheses against an alpha-level of 0.01 .

First, to assess the perceived effect of VAAs on political knowledge, we ran three linear regression models. In the first model, we predict the score on our knowledge question from several demographic variables: age, gender, and educational level. In the second model, we add four personality characteristics: NfC, internal political 
efficacy, external political efficacy, and vote certainty. In the third model, we add the effect of the prime reason for VAA usage.

Second, to estimate which kind of respondents perceive the effect of VAAs on vote choice to be largest, we recoded our perceptual measure of the effect on vote choice (see Appendix 3) into a binary variable. The answering categories 'Kieskompas has made me doubt my party preferences' and 'Kieskompas has determined my party preferences' were taken to indicate an effect on vote choice (code 1), whereas the answering categories 'Kieskompas has not affected my party preferences' and 'Kieskompas has confirmed my party preferences' were coded to reflect no effect (code 0 ). This binary variable was predicted in three regression analyses in which the same predictor variables were entered for analysing the perceived knowledge effect.

Third, for the behavioural assessment of the effect on vote choice, we estimate whether (1) or not (0) the respondent voted for the recommended party. This variable was constructed based on the match between the actual voting advice given by the VAA and the party the respondent reported to have voted for in the actual election. Again we entered the same predictor variables as in the earlier described models into the equation. In addition to those factors we also included the PTV of the party the respondent voted for. In this way our analysis provides an insight into what kind of respondents are more likely to vote for the party recommended by the VAA, while controlling for the likelihood the respondent would already vote for the recommended party. It is important to control for the PTV, as both Wall et al. (2014) and Ruusuvirta and Rosema (2009) show that the effect of VAAs depends on the correspondence of the advice with the VAA user's pre-existing preferences.

As a fourth step, we performed all the analyses described above again on a data set that was weighted to the population of KiesKompas users for age, gender, and educational level. This way we can establish whether the effects found in the uncorrected post-election sample are robust. In addition, we performed our analyses on the selfperceived measures in the pop-up survey sample in weighted and un-weighted form. This way we can check if the same predictor variables are important in a larger data set $(N=36,294)$ gathered at a different point in time, that is, directly after VAA usage. Moreover, in order to isolate a possible effect of the timing of question asking, we performed the analyses on a subset of the pop-up sample, consisting of those respondents who also participated in our post-election study. A comparison of the results of this - weighted and un-weighted - sample with the post-election sample allows for drawing conclusions about the effect of timing in measuring VAA effects. 5

\section{Results}

\section{Political Knowledge}

Results of the regression models used for predicting the perceived effect of VAAs on knowledge and vote choice are displayed in Table 2. As can be seen the intercept of the regression model is 3.17. Relating this score to a 5-point scale on which higher 
Table 2. Parameter estimates of the self-perceived position on political knowledge

\begin{tabular}{|c|c|c|c|}
\hline & Model 1 & Model 2 & Model 3 \\
\hline Intercept & $3.536(0.060)$ & $3.476(0.119)$ & $3.174(0.123)$ \\
\hline Gender: female ${ }^{a}$ & $0.088(0.030)^{*}$ & $0.059(0.030)$ & $0.043(0.030)$ \\
\hline Age: $35-54^{\mathrm{b}}$ & $-0.143(0.038)^{* *}$ & $-0.132(0.038)^{*}$ & $-0.126(0.038)^{*}$ \\
\hline Age: $55+{ }^{\mathrm{b}}$ & $-0.391(0.038)^{* *}$ & $-0.373(0.038)^{* *}$ & $-0.359(0.037)^{* *}$ \\
\hline Educational level: medium ${ }^{\mathrm{c}}$ & $0.044(0.054)$ & $0.035(0.054)$ & $0.046(0.053)$ \\
\hline Educational level: high $^{\mathrm{c}}$ & $0.123(0.051)$ & $0.119(0.051)$ & $0.138(0.051)^{*}$ \\
\hline Need for cognition & & $0.044(0.019)$ & $0.050(0.019)^{*}$ \\
\hline Internal political efficacy & & $-0.044(0.017)$ & $-0.040(0.017)$ \\
\hline External political efficacy & & $-0.009(0.017)$ & $-0.012(0.017)$ \\
\hline Certainty: doubts between parties ${ }^{\mathrm{d}}$ & & $0.164(0.045)^{* *}$ & $0.159(0.045)^{* *}$ \\
\hline Certainty: certain about choice ${ }^{\mathrm{d}}$ & & $-0.038(0.047)$ & $0.023(0.049)$ \\
\hline Reason: gaining insight ${ }^{\mathrm{e}}$ & & & $0.489(0.044)^{* *}$ \\
\hline Reason: checking initial idea ${ }^{\mathrm{e}}$ & & & $0.288(0.031)^{* *}$ \\
\hline Reason: deciding content vote ${ }^{\mathrm{e}}$ & & & $0.282(0.045)^{* *}$ \\
\hline$N$ & 5313 & 5313 & 5313 \\
\hline$R^{2}$ & 0.031 & 0.043 & 0.068 \\
\hline$R^{2}$ change & 0.031 & 0.012 & 0.026 \\
\hline
\end{tabular}

Note: Standard error between parentheses.

${ }^{a}$ Reference category: males.

${ }^{\mathrm{b}}$ Reference category: $18-34$.

${ }^{\mathrm{c}}$ Reference category: low educational level.

${ }^{\mathrm{d}}$ Reference category: does not know whom to vote for.

${ }^{\mathrm{e}}$ Reference category: fun test.

${ }^{*} p<.01{ }^{* *} p<.001$.

values represent more positive evaluations of the knowledge effect, VAA users in the reference category (males, who are young, lower educated, associated with a low$\mathrm{NfC}$, etc.) on average feel that VAA usage had a positive effect on their political knowledge.

Table 2 also shows that there are two demographic variables that affect the perceived knowledge effect: age and educational level. First, younger VAA users (18-34) report a larger increase in knowledge than medium-aged (35-54) and older VAA users $(55+)$. The difference between younger and older VAA users runs up to about 0.36 scale points. So, while the average knowledge score for younger VAA users is 3.17, it is only about 2.82 for older VAA users. Second, higher educated VAA users report to learn more from VAAs than lower educated VAA users. In terms of scale points, the higher educated VAA users report the effect of VAAs on political knowledge to be about 0.12 higher than the lower educated. Altogether, the demographic variables entered into the equation explain about 3 per cent of the variance, which is a rather modest percentage. 
The respondent dispositions in model 2 explain even less variance than the demographic characteristics in model 1 (1.2 per cent). This explained variance can largely be attributed to effects of $\mathrm{NfC}$ and vote certainty. In line with our hypotheses, individuals who have a higher NfC, learn more from VAAs than users with a lower NfC. In terms of scale points, the difference between VAA users with a low versus a high$\mathrm{NfC}$ runs up to about 0.25 scale points. Furthermore, individuals who are in doubt about whom to vote before starting the VAA, learn more from VAAs than those users who already know whom to vote, but also as compared to those individuals who do not know at all whom to vote, this difference runs up to 0.16 scale points on a 5-points scale.

The only situational characteristic entered into the model is the prime reason for VAA usage. As can be read from Table 2, this variable by itself explains about 2.5 per cent of the variance. The effect of the primary reason for VAA usage reads that VAA users who regard the VAA to be just a fun test learn much less from their VAA usage than VAA users who turn to a VAA to gain knowledge on their initial preferences, or who decide for which party to vote. The difference between these different groups of VAA users is quite large -0.5 scale point.

In sum, in line with our hypotheses, our results show a larger knowledge increase for individuals with a high-NfC (H1.1), individuals who are uncertain or whom to vote (H1.3), and individuals who consider the VAA to be a serious advice instrument (H1.4). Our results provide no support for an effect of political efficacy (H1.2).

\section{The Perceived Effect of VAAs on Vote Choice}

Table 3 shows the parameter estimates of our model predicting the perceived effect of VAAs on vote choice.

As Table 3 shows 14.8 per cent of the respondents in the reference category (males, who are young, lower educated, associated with a low-NfC) indicated that the VAA determined their vote choice or made them hesitant about whom to vote. As demographic variables do not make a significant contribution to predicting vote choice, we may actually apply this percentage to all individuals of all genders, age groups, and levels of education.

The respondent dispositions added in model 2 explain a substantial part of the total variance in scores (about 13 per cent). The effects of internal efficacy and vote certainty are of particular importance as these variables significantly contribute to the regression model. The higher an individual's internal efficacy, the less likely one is to indicate that KiesKompas influenced their vote. To get an impression of the size of this effect, the regression weights in Table 3 are translated into percentages. When all other parameters are set to the default, individuals who report to have a low efficacy score report to be affected by the advice in 14.8 per cent of the cases, versus 7 per cent of the respondents with the highest efficacy scores. Results also show that the more certain a VAA user is about his vote choice before turning to the VAA, the less likely he or she is to perceive the voting advice to have an effect. When all other parameters are set to the default, individuals who report to 
Table 3. Parameter estimates (in Logits, standard error and percentages between brackets) of whether) (1) or not (0) the respondent perceived an effect of VAA on vote choice

\begin{tabular}{|c|c|c|c|}
\hline & Model 1 & Model 2 & Model 3 \\
\hline Intercept & $-1.870(0.179)$ & $-0.602(0.361)$ & $-1.754(0.390 ; 14.75 \%)$ \\
\hline Gender: female ${ }^{a}$ & $0.516(0.088)^{* *}$ & $0.276(0.093)^{*}$ & $0.220(0.095)$ \\
\hline Age: $35-54^{\mathrm{b}}$ & $0.010(0.117)$ & $-0.008(0.122)$ & $0.005(0.123)$ \\
\hline Age: $55+^{\mathrm{b}}$ & $-0.190(0.118)$ & $-0.190(0.123)$ & $-0.165(0.125)$ \\
\hline $\begin{array}{l}\text { Educational level: } \\
\text { medium }^{c}\end{array}$ & $-0.035(0.160)$ & $-0.032(0.167)$ & $0.031(0.169)$ \\
\hline Educational level: high $^{\mathrm{c}}$ & $-0.284(0.152)$ & $0.119(0.160)$ & $-0.057(0.162)$ \\
\hline Need for cognition & & $0.040(0.062)$ & $0.091(0.063)$ \\
\hline Internal political efficacy & & $-0.179(0.052)^{*}$ & $-0.166(0.053)^{*}$ \\
\hline $\begin{array}{l}\text { External political } \\
\text { efficacy }\end{array}$ & & $0.087(0.050)$ & $0.061(0.051)$ \\
\hline $\begin{array}{l}\text { Certainty: doubts } \\
\text { between parties }\end{array}$ & & $-0.621(0.110)^{* *}$ & $-0.417(0.116)^{* *}$ \\
\hline $\begin{array}{l}\text { Certainty: certain about } \\
\text { choice }^{\mathrm{d}}\end{array}$ & & $-2.40(0.164)^{* *}$ & $-1.950(0.174)^{* *}$ \\
\hline Reason: gaining insight $\mathrm{e}^{\mathrm{e}}$ & & & $0.901(0.161)^{* *}$ \\
\hline $\begin{array}{l}\text { Reason: checking initial } \\
\text { idea }^{\mathrm{e}}\end{array}$ & & & $0.555(0.137)^{* *}$ \\
\hline $\begin{array}{l}\text { Reason: deciding } \\
\text { content vote }\end{array}$ & & & $1.307(0.147)^{* *}$ \\
\hline$N$ & 5372 & 5372 & 5372 \\
\hline Nagelkerke $R^{2}$ & 0.018 & 0.147 & 0.178 \\
\hline $\begin{array}{l}\text { Change in Nagelkerke } \\
R^{2}\end{array}$ & 0.018 & 0.129 & 0.031 \\
\hline
\end{tabular}

Note: Standard error and percentage between parentheses.

${ }^{a}$ Reference category: males.

${ }^{\mathrm{b}}$ Reference category: $18-34$.

${ }^{\mathrm{c}}$ Reference category: low.

${ }^{\mathrm{d}}$ Reference category: does not know whom to vote for.

${ }^{\mathrm{e}}$ Reference category: fun test.

${ }^{*} p<.01{ }^{* *} p<.001$.

be uncertain about their vote choice are affected more (14.8 per cent) than individuals who are quite certain of their vote choice in advance ( 2.4 per cent).

Finally, results show that the prime reason for VAA usage is an important predictor (model 3). By itself it explains 3.1 per cent of the variance in scores. VAA users who consider the VAA to be just a fun test are not affected as much as respondents who turn to the VAA to determine their vote choice. Of the later, 39 per cent report to be influenced by the VAA when all other parameters in the model are set to the default. 
Overall, in line with our hypotheses, the perceived effect of VAA usage on vote choice is larger in general for individuals with a low internal efficacy (H2.2), for individuals who are uncertain in advance for whom to vote (H2.3) and for individuals who consider the VAA to be more than just a fun test $(\mathrm{H} 2.4)$. We found no evidence for an effect of NfC (H2.1).

\section{The Effect of VAAs on Vote Choice Measured with Behavioural Measures}

Table 4 shows the results of regression analyses predicting the effect of VAAs on vote choice as measured with behavioural measurements. As explained in the analysis section, this model includes the PTV of the advised party as a covariate in order to rule out the alternative explanation that the accordance between the advice and the party voted for is due to pre-existing preferences.

Table 4 shows that it is indeed important to control for the PTV of the advised party. The PTV score determines to a large extent whether or not a person votes for the party recommended. The higher the PTV for the advised party, the higher the likelihood the user will vote for the party recommended. When all parameters in the model are set to the default, the likelihood of voting for the party recommended by the VAA fluctuated between 6 per cent (PTV of 0) and 20.5 per cent (PTV of 10). This suggests that the more serious a party was previously considered by the VAA user, the higher the likelihood that he or she will vote for this party when it is recommended.

When controlled for the PTV, we find that age is the only demographic variable that makes a significant contribution to the model: younger (18-34) and mediumaged (35-54) VAA users are more likely to vote for the recommended party than older $(55+)$ voters. When all other parameters are set to the default, the estimated percentage of older VAA users who vote for the party recommended is as low as 3.8 per cent whereas the default value of 6 per cent applies to the young and medium-aged.

Contrary to what we have seen for the perceptual measurements, respondent dispositions added in model 2 play only a minor role in explaining vote choice (1.4 per cent variance explained). Internal efficacy is the only predictor that shows an effect and the effect is contrary to expectations - voters who have a high internal political efficacy are more likely to vote for the party recommended than voters with low efficacy scores. When all other parameters are set to the default, the estimated difference between voters with a low versus a high efficacy is about 6.6 per cent. This means that about 12.6 per cent of users with the highest internal efficacy score vote for the party recommended.

Finally, results show that the primary reason for VAA usage does not make a significant contribution to explaining the effect on vote choice. Adding this predictor to the model does not increase the percentage of variance explained.

In sum, results show that individuals more often vote in correspondence with the VAA advice if they were already seriously considering voting for that party in advance. In addition, when controlled for PTV, we find an effect of internal efficacy, 
Table 4. Parameter estimates (in Logits, standard error and percentages between brackets) of whether (1) or not (0) the respondent voted for the party recommended

\begin{tabular}{|c|c|c|c|}
\hline & Model 1 & Model 2 & Model 3 \\
\hline Intercept & $-1.731(0.175 ; 15.0 \%)^{* *}$ & $-2.799(0.344 ; 5.7 \%)^{* *}$ & $-2.748(0.358 ; 6.0 \%)^{* *}$ \\
\hline Gender: female $^{\mathrm{a}}$ & $-0.163(0.081)$ & $-0.066(0.083)$ & $-0.064(0.083)$ \\
\hline Age: $35-54^{\mathrm{b}}$ & $-0.191(0.095)$ & $-0.169(0.096)$ & $-0.166(0.096)$ \\
\hline Age: $55+^{\mathrm{b}}$ & $-0.517(0.097)^{* *}$ & $-0.493(0.098)^{* *}$ & $-0.490(0.098)^{* *}$ \\
\hline Educational level: medium ${ }^{\mathrm{c}}$ & $-0.138(0.161)$ & $-0.156(0.162)$ & $-0.159(0.162)$ \\
\hline Educational level: high $^{\mathrm{c}}$ & $0.281(0.149)$ & $0.182(0.151)$ & $0.180(0.151)$ \\
\hline Need for cognition & & $0.117(0.054)$ & $0.113(0.054)$ \\
\hline Internal political efficacy & & $0.163(0.049)^{*}$ & $0.162(0.049)^{*}$ \\
\hline External political efficacy & & $-0.112(0.048)$ & $-0.111(0.048)$ \\
\hline Certainty: doubts between parties ${ }^{\mathrm{d}}$ & & $0.136(0.134)$ & $0.111(0.140)$ \\
\hline Certainty: certain about choice ${ }^{\mathrm{d}}$ & & $0.274(0.140)$ & $0.241(0.149)$ \\
\hline Reason: gaining insight ${ }^{\mathrm{e}}$ & & & $0.053(0.119)$ \\
\hline Reason: checking initial idea ${ }^{\mathrm{e}}$ & & & $-0.008(0.085)$ \\
\hline Reason: deciding content vote ${ }^{\mathrm{e}}$ & & & $-0.086(0.130)$ \\
\hline PTV advised party & $0.143(0.011)^{* *}$ & $0.139(0.011)^{* *}$ & $0.139(0.011)^{* *}$ \\
\hline$N$ & 4881 & 4881 & 4881 \\
\hline Nagelkerke $R^{2}$ & 0.089 & 0.103 & 0.103 \\
\hline Change in Nagelkerke $R^{2}$ & 0.089 & 0.014 & 0.000 \\
\hline
\end{tabular}

Note: Standard error and percentage between parentheses.

${ }^{a}$ Reference category: males.

${ }^{\mathrm{b}}$ Reference category: $18-34$.

${ }^{\mathrm{c}}$ Reference category: low.

${ }^{\mathrm{d}}$ Reference category: does not know whom to vote for.

${ }^{\mathrm{e}}$ Reference category: fun test.

${ }^{*} p<.01{ }^{* *} p<.001$. 
but it is in the opposite direction than that expected (H2.1) - individuals with high efficacy scores are more likely to vote for the party recommended by the VAA. Our data also show no support for an effect of NfC (H.2.1), vote certainty prior to VAA usage (2.3), and primary reason for VAA usage (2.4).

\section{Robustness Checks}

As the post-election survey sample did not show to be representative for KiesKompas users, we performed all analyses again on the post-election sample, weighted to KiesKompas users for gender, age, and educational level. All effects reported in the previous sections are also observed in this weighted sample. Therefore, our results can be generalised to the population of KiesKompas users.

We also performed the analyses on the perceptual dependent variables again, both on the full pop-up survey sample and on a selection of the pop-up sample consisting of those respondents who also participated in the post-election sample. With one exception all effects reported in the results section also appeared in the full and the smaller pop-up sample, both in weighted and un-weighted form. The only exception concerns the effect of educational level for the knowledge scores. While in the postelection sample a positive effect of educational level was shown (higher educated VAA users report a larger knowledge increase than lower educated VAA users), in most of our pop-up samples the effect was in an opposite direction showing a negative effect of educational level. The fact that a positive effect of educational level was only present in the post-election survey may indicate that higher educated VAA users in particular use the VAA as a stepping stone to look for more information about politics and therefore learn more after some time has passed. ${ }^{6}$

\section{Conclusion and Discussion}

In many democracies millions of voters lack sufficient political knowledge and (therefore) sometimes decide not to vote at all or they vote for a party that poorly matches their preferences (Delli Carpini \& Keeter, 1996). In this study of VAA users at the 2012 Dutch National Election results show that in general, VAA increased users' knowledge of political parties and party standpoints. These knowledge effects were larger for certain groups of VAA users: the young, voters with low levels of $\mathrm{NfC}$ and those certain about their vote choice beforehand. VAA users who consider the VAA to be a serious advice instrument report particularly large knowledge effects.

Results also show that approximately 15 per cent of the VAA users experienced an influence on their vote choice. The perceived effect of VAAs on vote choice was larger for users with a low internal efficacy, a limited certainty about their vote choice before turning to the VAA and users who consider the VAA to be a serious advice instrument. Hence, there is a clear parallel between those groups of VAA users who experience a larger knowledge increase and those experiencing a larger effect on vote choice. 
Behavioural measures of the effect of VAAs on vote choice, however, show a different picture. While individuals with low internal efficacy scores perceived the effect on vote choice to be large, people with high efficacy scores voted for the party recommended by the VAA relatively often. In addition, uncertain VAA users and VAA users who consider the VAA to be a serious advice instrument do not vote for the recommended party more often. Instead, the young were found to vote for the party recommended relatively often. In short, there is a poor match between behavioural and perceptual measurements of the effect of VAAs on vote choice.

So, what do these results imply for the contribution of VAAs to democracy? On the one hand, there is reason to conclude that VAAs have a positive influence on democracy - VAA users generally experience an increase in political knowledge which suggests that VAAs indeed help users to inform themselves about politics. In addition, we found that those groups of VAA users who experienced a large effect on political knowledge also experienced the effect on vote choice to be relatively large. This provides indirect evidence to conclude that VAAs affect vote choices because they are based on knowledge that is more elaborate.

On the other hand, there is reason to query the positive contribution of VAAs to democracy. While the current research has shown that VAAs indeed increase the perceived political knowledge of their users, this does not necessarily mean that VAA users actually know more than they did before; earlier studies show a poor relation between perceived and factual knowledge (e.g. Park, 2001). Our study did not investigate actual political knowledge, but it did show a similar gap between perception and fact for the effect on vote choice. Taking those previous studies into account, as well as the discrepancies between perceptual and behavioural measurements found here, the conclusion would be that in order to pinpoint the exact contribution of VAAs, more research is needed to disentangle to what extent VAAs shape both felt and actual knowledge. We are currently conducting qualitative think-aloud studies that allow for a reflection on this issue. In these studies VAA users are asked to verbalise their thoughts while working with a VAA. This sheds light on what kinds of additional knowledge users gain such as an insight into issues that are at stake in certain elections.

Another reason to query the positive contribution of VAAs to democracy is because one may question the causal relation between the effect of knowledge and vote choice. In this study the effects of VAAs on knowledge and vote choice have been investigated in two separate analyses, and hence, in an indirect way. In order to investigate more directly to what extent VAAs affect vote choices because they affect political knowledge, mediation analysis should be performed. A prerequisite for such an analysis is that the amount of variance explained in the mediating dependent variable, in this case knowledge, is substantial (Lord \& Novick, 1968). Based on the total percentage of variance explained in our knowledge measure (about 7 per cent, see Table 2), no such analysis could be performed.

From a normative viewpoint one may question if 'information about the standpoints of political parties' is the most desirable type of information voters need to function well in democracy. Throughout this article we have assumed that this is indeed the case, hence we have relied on a Downsian perspective on democracy 
(Downs, 1957). In a deliberative perspective on democracy (e.g. Habermas, 1994) it is assumed that voters do not merely need information about parties and their issue positions but rather they should learn to see themselves as "co-authors of law and public policy' (Fossen \& Anderson, 2014: 247). In order to stimulate such behaviour, different knowledge and skills are required. For example, in a deliberative democracy citizens should be able to find each other online in order to discuss how current political issues can best be solved. Hence, from the perspective of this different model of democracy, a very different type of VAA would probably have to be developed in order to stimulate a well-functioning democracy (see Fossen \& Anderson, 2014, for further suggestions; for descriptions of VAAs that include a networking element, see Katakis et al., 2014).

While more research is needed to pinpoint exactly how VAAs contribute to democracy, it is nevertheless interesting to speculate about how the results of the current study might transfer to other countries and Ireland in particular. The overall positive effect of VAAs on both political knowledge and vote choice that we have observed here, has also been reported for an abundance of other countries with various different types of voting systems (e.g. Ladner, 2012). Therefore, it is likely that in Ireland positive effects of VAA usage on knowledge and vote choice will be found. At the same time, we think that the average impact on knowledge and vote choice among Irish VAA users is currently a bit more modest than in the Netherlands, because VAA usage in Ireland is not (yet) widespread (Wall et al., 2009 reported that www. pickyourparty.ie was accessed about 30,000 times). When VAAs are newly introduced in a country the average user is disproportionately often male, highly educated, young and interested in politics (Wall et al., 2009; Marschall, 2014). The typical Irish VAA user seems to match this picture (Wall et al., 2009) while in the Netherlands the imbalances in the composition of the general population still exist, but have decreased over time. Due to these differences in the composition of population of VAA users, we expect Irish VAAs to reach relatively more 'political junkies' as compared to the Dutch case, and therefore we expect the average effects on knowledge and vote choice to be more modest. Future empirical studies are needed to test this prediction.

\section{Disclosure statement}

No potential conflict of interest was reported by the authors.

\section{Funding}

This work was supported by the Nederlandse organisatie voor Wetenschappelijk Onderzoek (NWO) [grant number 321-89-003].

\section{Notes}

1. We did not create a log file if the Kieskompas user was under 18 on election day, when the user answered all 30 VAA statements within one minute, when the user exposed straight-lining on the 
VAA statements, when the user did not answer the VAA statements at all, and when the VAA user indicated he or she was 100 years of age or older.

2. In a panel study during the municipality elections in the city of Utrecht, we measured each of these constructs again but this time with two or three questions. These measurements showed to have an acceptable reliability (Cronbach's alpha between .63 and .75 ).

3. With the KiesKompas population, we refer to the group of KiesKompas users who entered their demographic variables on the first page of the tool.

4. The same biases apply when we compare our samples to the population of Dutch voters. We did not weight our data to the Dutch population, as we only attempt to draw conclusions about the effects of VAAs for people who use a VAA.

5. We also ran regression models specifying not only all main effects, but also several interactions which the literature suggest might be of importance. In most cases, the interaction terms did not reach statistical significance, and adding them only slightly improved the predictive value of the model. Therefore, we decided not to report the models including interaction terms.

6. Except for educational level, all variables that made a significant contribution to predicting the perceived effect on political knowledge (Table 2) and the perceived effect on vote choice (see Table 3 ), showed effects in all of our samples. In addition to these robust effects, we also observed some extra effects. As these additional effects always occurred in only one or two of our samples, these effects are not robust. Therefore, we do not discuss them in the main text.

\section{References}

Aarts, K. \& Van der Kolk, H. (2007) The parliamentary election in the Netherlands, Electoral Studies, 26(4), pp. 797-837.

Andreadis, I. \& Wall, M. (2014) The impact of voting advice applications on vote choice, in: D. Garzia \& S. Marschall (Eds.) Matching Voters with Parties and Candidates, Voting Advice Applications in Comparative Perspective, pp. 115-128 (Colchester: ECPR Press).

Cacioppo, J.T. \& Petty, R.E. (1982) The need for cognition, Journal of Personality and Social Psychology, 42(1), pp. 116-131.

Cacioppo, J.T., Petty, R.E. \& Kao, C.F. (1984) The efficient assessment of need for cognition, Journal of Personality Assessment, 48(3), pp. 306-307.

Dalton, R.J. (2000) The decline of party identifications, in: R.J. Dalton \& M.P. Wattenberg (Eds.) Parties without Partisans: Political Change in Advanced Industrial Democracies, pp. 19-37 (Oxford: Oxford University Press).

Dalton, R.J. (2002) Political cleavages, issues, and electoral change, in: L. LeDuc, R. Niemi \& P. Norris (Eds.) Comparing Democracies 2: New Challenges in the Study of Elections and Voting, pp. 189-209 (London: Sage).

De Graaf, J. 2010 The irresistible rise of Stemwijzer, in: L. Cedroni \& D. Garzia (Eds.) Voting Advice Applications in Europe: The State of the Art, pp. 35-46 (Napoli: Scriptaweb).

Delli Carpini, M. X. \& Keeter, S. (1996) What Americans know about Politics and Why it Matters (New Haven, CT: Yale University Press).

De Rosa, R. (2010) Cabina-elettorale.it (provides advice to Italian voters since 2009), in: L. Cedroni \& D. Garzia (Eds.) Voting Advice Applications in Europe: The State of the Art, pp. 247-257 (Napoli: Scriptaweb).

Downs, A. (1957) An Economic Theory of Democracy (New York: Harper Collins).

Dumont, P. \& Kies, R. (2012) Smartvote.lu: usage and impact of the first VAA in Luxembourg, International Journal of Electronic Governance, 5(3/4), pp. 388-410.

Farnsworth, S.J. \& Owen, D. (2004) Internet use and the 2000 presidential election, Electoral Studies, 23(3), pp. 415-429.

Finkel, S.E. (1985). Reciprocal effects of participation and political efficacy: a panel analysis, American Journal of Political Science, 29(4), pp. 891-913. 
Fossen, T. \& Anderson, J. (2014) What's the point of voting advice applications? Competing perspectives on democracy and citizenship, Electoral Studies, 36, pp. 244-251.

Franklin, M.N., Mackie, T.T. \& Valen, H. (1992) Electoral Change: Responses to Evolving Social and Attitudinal Structures in Western Societies (Cambridge: Cambridge University press).

Garzia, D. (2010) The effects of VAAs on users' voting behaviour: an overview, in: L. Cedroni \& D. Garzia (Eds.) Voting Advice Applications in Europe: The State of the Art, pp. 13-33 (Napoli: Scriptaweb).

Garzia, D. \& Marschall, S. (2012) Voting Advice Applications under review: the state of research, International Journal of Electronic Governance, 5(3/4), pp. 203-222.

Habermas, J. (1994) Three normative models of democracy, Constellations, 1(1), pp. 1-10.

Hallahan, K. (2009) Need for cognition as motivation to process publicity and advertising, Journal of Promotion Management, 14(3/4), pp. 169-194.

Hirzalla, F., Van Zoonen, L. \& De Ridder, J. (2010) Internet use and political participation: reflections on the mobilization/normalization controversy, The Information Society, 27(1), pp. 1-15.

Kaid, L.L., McKinney, M.S. \& Tedesco, J.C. (2007) Introduction: political information efficacy and young voters, American Behavioral Scientist, 50(9), pp. 1093-1111.

Katakis, I., Tsapatsoulis, N., Mendez, F., Triga, V. \& Djouvas, C. (2014) Social voting advice applications: definitions, challenges, datasets and evaluation, IEEE Transactions on Cybernetics, 44(7), pp. 10391052.

Kaye, B.K. \& Johnson, T.J. (2004) Web for all reasons: uses and gratifications of Internet components for political information, Telematics and Informatics, 21(3), pp. 197-223.

Kleinnijenhuis, J., Scholten, O., Van Atteveldt, W., Van Hoof, A., Krouwel, A., Oegema, D., De Ridder, J.A., Ruigrok, N. \& Takens, J. (2007) Nederland Vijfstromenland. De Rol van Media en Stemwijzers bij de Verkiezingen van 2006 (Amsterdam: Uitgeverij Bert Bakker).

Ladner, A. (2012) Voting Advice Applications - Impact on Voting Decisions in the 2011 Swiss National Elections. Paper presented at the 62nd Political Studies Association Annual International Conference, April 3-5, Belfast, available at: http://www.researchgate.net/publication/261495685_Voting_advice_ applications-impact_on_voting_decisions_in_the_2011_Swiss_national_elections

Ladner, A., Fivaz, J. \& Nadig, G. (2009) Voting assistance applications as tools to increase political participation and improve civic education, in: M. Print \& H. Milner (Eds.) Civic Education and Youth Political Participation, pp. 43-59 (Rotterdam/Boston/Tajpei: Sense).

Ladner, A., Fivaz, J. \& Pianzola, J. (2012) Voting advice applications and party choice: evidence from Smartvote users in Switzerland, International Journal of Electronic Governance, 5(3-4), 367-387.

Lord, F.M. \& Novick, M.R. (1968) Statistical Theories of Mental Test Scores (Reading, MA: AddisonWesley).

Marschall, S. (2005) Idee und Wirkung des Wahl-O-Mat, Aus Politik und Zeitgeschichte (APuZ), 51-52, pp. $41-46$.

Marschall, S. (2014) Profiling users, in: D. Garzia \& S. Marschall (Eds.) Matching Voters with Parties and Candidates, Voting Advice Applications in Comparative Perspective, pp. 93-106 (Colchester: ECPR Press).

Murphy, G. \& Reidy, T. (2012) Presidential elections in Ireland: from partisan predictability to the end of loyalty, Irish Political Studies, 27(4), pp. 615-634.

Mykkänen, J., Moring, T. (2006) Dealigned Politics Comes of age? The Effects of Online Candidate Selectors on Finnish Voters. Paper presented at the conference of politics on the Internet: New forms of media for political action, November 25, Tampere, available at: http://www.edemocracy. uta.fi/eng/haefile.php?f=132

Niemi, R.G., Craig, S.C. \& Mattei, F. (1991) Measuring internal political efficacy in the 1988 National Election Study, American Political Science Review, 85(4), pp. 1407-1413.

Park, C.-Y. (2001) News media exposure and self-perceived knowledge: the illusion of knowing, International Journal of Public Opinion Research, 13(4), pp. 419-425.

Popkin, S.L. \& Dimock, M.A. (1999) Citizen competence and democratic institutions, in: S.L. Elkin \& K.E. Sołtan (Eds.) Citizen Competence and Democratic Institutions, pp. 117-146 (Pennsylvania: The Pennsylvania State University Press). 


\section{$614 N$. Kamoen et al.}

Rudolph, T.J. \& Popp, E. (2007) An information processing theory of ambivalence, Political Psychology, 28(5), pp. 563-585.

Ruusuvirta, O. \& Rosema, M. (2009) Do Online Vote Selectors Influence Electoral Participation and the Direction of the Vote? Paper presented at the ECPR general conference, September 10-12, Potsdam, available at: http://www.utwente.nl/bms/pa/staff/rosema/publications/conference_papers/paper_ ruusuvirta_and_rosema_ec.pdf

Van der Eijk, C., Van der Brug, W., Kroh, M. \& Franklin, M. (2006) Rethinking the dependent variable in voting behavior: on the measurement and analysis of electoral utilities, Electoral Studies, 25(3), pp. $424-447$.

Walgrave, S., Van Aelst, P. \& Nuytemans, M. (2008) 'Do the vote test': the electoral effects of a popular vote advice application at the 2004 Belgian elections, Acta Politica, 43(1), pp. 50-70.

Wall, M., Krouwel, A.P.M., and Vitiello, T. (2014) Do voters follow the recommendations of voter advice application websites? A study of the effect of kieskompas.nl on its users' vote choices in the 2010 Dutch Legislative Elections, Party Politics, 20(3) pp. 416-428.

Wall, M., Sudulich, A.L., Corstello, R. \& Leon, E. (2009) Picking your party online - an investigation of Ireland's first online voting advice application, Information Polity, 14, pp. 203-218.

Zaller, J.R. (1992) The Nature and Origins of Mass Opinion. (Cambridge: Cambridge University Press.

\section{Appendix 1: Example of VAA Statement and Implicit and Explicit Voting Advice}
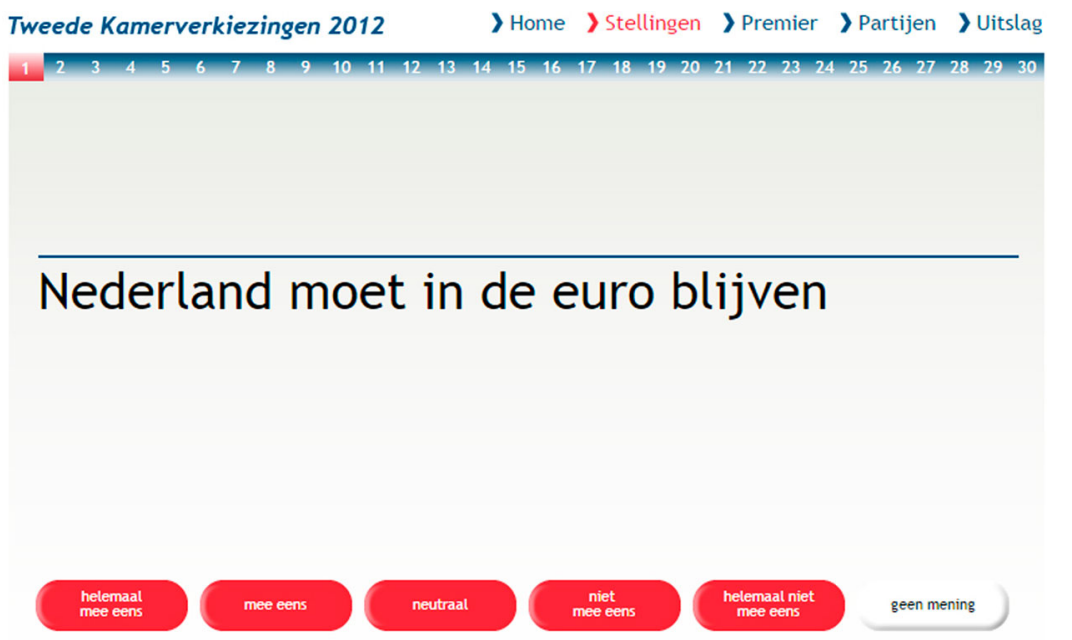

Figure A1. Example of VAA question taken from Kieskompas (Vote Compass) 2012 for the Dutch general elections.

Note: The question reads The Netherlands should stay in the Euro zone and the response categories range from completely agree to completely disagree supplemented with a no opinion option. 


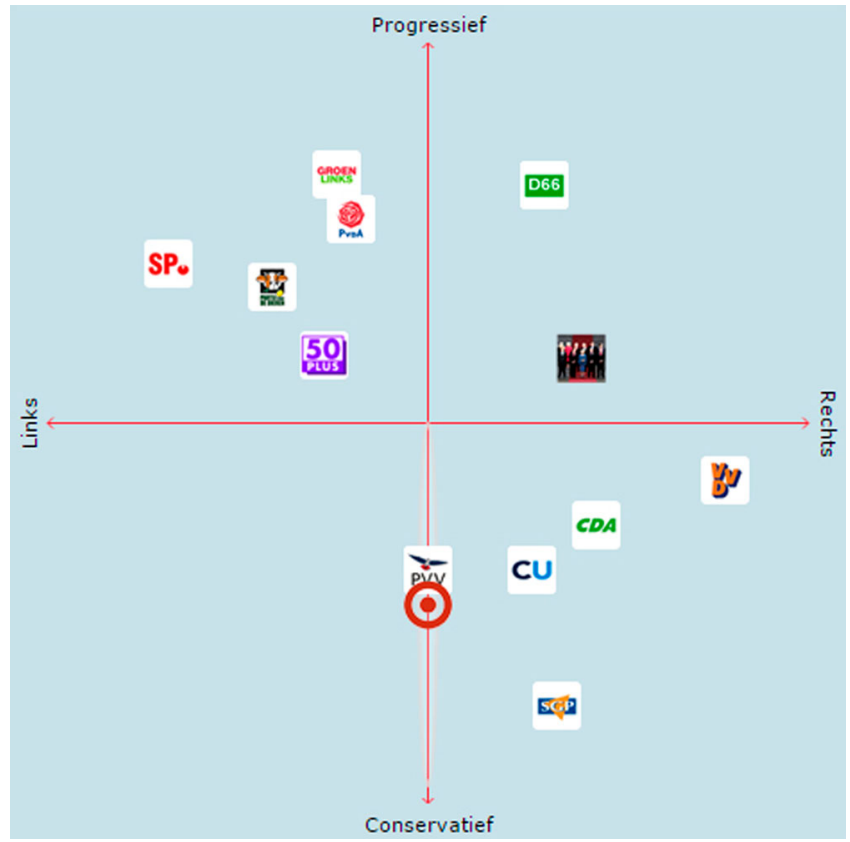

Figure A2. Example of VAA advice taken from Kieskompas (Vote Compass) 2012. Note: The axis indicate the political spectrum with a political left-right axis (horizontal) and a progressive-conservative axis (vertical). The icons indicate the political parties in this spectrum and the red dot indicates the position of the user. 


\section{Meeste overeenstemming met: GROENLINKS}

U bent het op 19 punten oneens met GroenLinks

\begin{tabular}{|l|l|}
\hline \multicolumn{1}{|l|}{ GroenLinks } & \\
\hline SP & \\
\hline Partij voor de Dieren & \\
\hline 50Plus & \\
\hline VVD & \\
\hline PvdA & \\
\hline PVV & \\
\hline D66 & \\
\hline CDA & \\
\hline ChristenUnie & \\
\hline SGP & \\
\hline Y U bent het op 7 punten eens met SGP \\
\hline
\end{tabular}

Figure A3. Example of VAA advice taken from Stemwijzer (Vote Wiser) 2012. Note: The text reads Most agreement with the Green Left party. In addition, the advice consists of a list of political parties, ranked for the match with the user's answers. Above the list it says that the user disagrees with the Green Left party on 19 issues.

\section{Appendix 2: Questions before Answering the KiesKompas Political Statements}

(GENDER) What is your gender?

- Male

- Female

(AGE) What is your year of birth?

- List ranging from 1910 - present

The answers to this question are recoded into young (18-34), medium-aged (35-54) and old (55+). This labelling is based on Ladner, Fivaz and Painzola (2012).

(EDUCATIONAL LEVEL) What is the level of your highest attained education? 
- University doctoral of Master

- University Bachelor/ College degree Bachelor

- HAVO/VWO superstructure / college degree or university propaedeutic

- MBO

- Finished MAVO/HAVO or HAVO/VWO substructure

- $\mathrm{LBO} / \mathrm{VMBO} / \mathrm{VBO}$

- No schooling/primary school

- Don't know/no opinion

As in previous studies (e.g. Ladner et al., 2012; Ladner et al., 2009) the answers to this question are recoded into high (1st and 2nd category), medium (3rd, 4th, 5th category) and low (6th and 7th category). 'Don't know'-answers were recoded as missing.

(CERTAINTY) How certain are you about your vote choice?

- Sure whom to vote for

- Hesitating between parties

- I don't know whom to vote for yet

- I am not going to vote

Due to a low number of responses for 'I am not going to vote' these answers were recoded as missing.

\section{Appendix 3: Questions in the Pop-up after Receiving a Voting Advice}

(REASON FOR VAA USAGE) What is the most important reason for you to use Kieskompas?

- To gain more insight in the positions of parties

- To check if I actually agree with the party I intend to vote for

- To figure out which party to vote for

- Fun test to think about or discuss with others

These categories are based on the reasons for VAA usage discussed in Rosema and Ruusuvirta (2009) and on the categories of reasons for political internet usage (Kaye \& Johnson, 2004).

(NEED FOR COGNITION) I enjoy thinking about issues, even though they don't concern myself personally. Agree 00000 Disagree 0 No opinion

This question combines question 1 (I really enjoy a task that involves coming up with new solutions to problems) and 12 (I usually end up deliberating about issues even when they do not affect me personally) of the official scale for measuring Need for Cognition (Cacioppo \& Petty, 1982). Both of these questions show high 
factor loadings for the scale and they are also included into the shortlist of NFC questions (Cacioppo et al.,1984). In addition, the current question is relevant in a political context, which not all NCF items are.

(INTERNAL EFFICACY) I believe I really understand the issues our country is facing at the moment. Agree 00000 Disagree 0 No opinion

(EXTERNAL EFFICACY) All political parties are similar so it does not matter which party I vote for. Agree 00000 Disagree 0 No opinion

These items are inspired by the questions in the scales for internal and external efficacy in Kaid, McKinney, Tedesco (2007).

(KNOWLEDGE) By using Kieskompas, I gained more understanding of the positions of political parties. Agree 00000 Disagree 0 No opinion

This question is based on Ladner's Smartvote improved my knowledge about the elections (2012), however we substituted knowledge about the elections into standpoints of political parties, which is more concrete.

(VOTE CHOICE) Using KiesKompas has ...

- Made me doubt my party preference

- Not affected my party preference

- Confirmed my party preference

- Determined my party preference

Previous studies have sometimes applied rather vague questions measuring the effect on vote choice (e.g. Ladner et al., 2009): Did the Smartvote recommendation have an impact on your voting decision? yes/no). In our question we tried to specify the different kinds of impact a VAA may have. 